Biol. Proced. Online 2004;6(1): 263-267.

doi:10.1251/bpo97

\title{
A simple and non-radioactive technique to study the effect of monophosphoesters on matrix vesicle-mediated calcification
}

\author{
Rama Garimella ${ }^{1}$, Joseph B. Sipe ${ }^{1}$ and H. Clarke Anderson ${ }^{1 *}$ \\ 'Department of Pathology and Laboratory Medicine, University of Kansas Medical Center, Kansas City, KS- \\ 66160. \\ *To whom correspondence should be addressed: H. Clarke Anderson, M.D., Department of Pathology \& \\ Laboratory Medicine, 3901 Rainbow Blvd., Kansas City, KS 66160. Phone: (913)-588-7474; Fax: (913)-588- \\ 7073; Email: handerso@kumc.edu
}

Submitted: July 22, 2004; Revised: October 14, 2004; Accepted: December 3, 2004; Published: December 16, 2004.

Indexing terms: Cartilage; Growth Plate; Bone and Bones; Calcification, Physiologic.

\begin{abstract}
A simple and non-radioactive technique based on $O$-cresolpthalein complexone assay was developed to study in vitro non-radioactive calcium $\left({ }^{40} \mathrm{Ca}\right)$ deposition by isolated matrix vesicles. Using this technique, the effect of various phosphoester substrates including ATP, AMP and $\beta$-GP on in vitro MV-calcification was studied. O-cresolpthalein complexone assay with non-radioactive calcium demonstrated that AMP or $\beta$-GP were more effective in promoting calcium deposition by isolated MVs than ATP. The application of this nonradioactive technique, which is highly sensitive and simple, would offer a useful alternative approach to the routinely used radiometric biomineralization assay which employs radioactive ${ }^{45} \mathrm{Ca}$.
\end{abstract}

\section{INTRODUCTION}

Matrix vesicles (MVs) are extracellular membrane invested entities, about $100 \mathrm{~nm}$ in size, located in the matrix of bone, cartilage and dentin (1). They serve as the initial site of calcification in all skeletal tissues. The mechanism of MVmediated mineralization is biphasic. In Phase-I, MVs initiate mineralization through the action of MV-associated phosphatases and calcium-binding phospholipids and proteins (1). MV phosphatases, including alkaline phosphatase (ALP), ATPase, 5'AMPase, and nucleoside triphosphate pyrophosphohydrolase (NTPPPH), play an active role in initiating MV mineralization (2). Phosphoester substrates such as ATP, AMP and PPi are hydrolyzed by MV phosphatases, thereby increasing the local concentration of orthophosphate and thus initiating mineralization (2). In Phase-II, the mineral formed inside the
MVs penetrates the vesicular membrane and in the presence of physiological concentrations of extravesicular $\mathrm{Ca}^{2+}, \mathrm{PO}^{3-}$, and pyrophosphate (PPi), the MV-initiated calcium phosphate mineral serves as nuclei for the formation of stellate clusters of needle-shaped biological apatite (1). In the presence of physiological extracellular concentrations of $\mathrm{Ca}^{2+}$ and $\mathrm{PO}^{2-}$, crystal propagation occurs. Calcifiable MVs can be isolated from collagenase-digested growth plates, and are generated by rat or chick chondrocytes or Saos-2 osteoblastic cells in culture (3-11). Ultra-structural examination of matrix vesicles of growth plate cartilage or primary chondrocyte cultures have demonstrated the presence of mineral in these vesicles which morphologically resembles apatite of calcified cartilage and bone (Fig. 1). MVmediated in vitro calcification has been more routinely demonstrated by measuring radioactive calcium $\left({ }^{45}\right.$ Calcium) deposition by isolated MVs. In this report, we describe a sensitive technique for studying in vitro calcification of isolated matrix

(C) 2004 by the author(s). This paper is Open Access and is published in Biological Procedures Online under license from the author(s). Copying, printing, redistribution and storage permitted. Journal C 1997-2004 Biological Procedures Online. 
vesicles using a non-radioactive calcium- $O$-cresolpthalein complexone (O-CPC) binding assay.

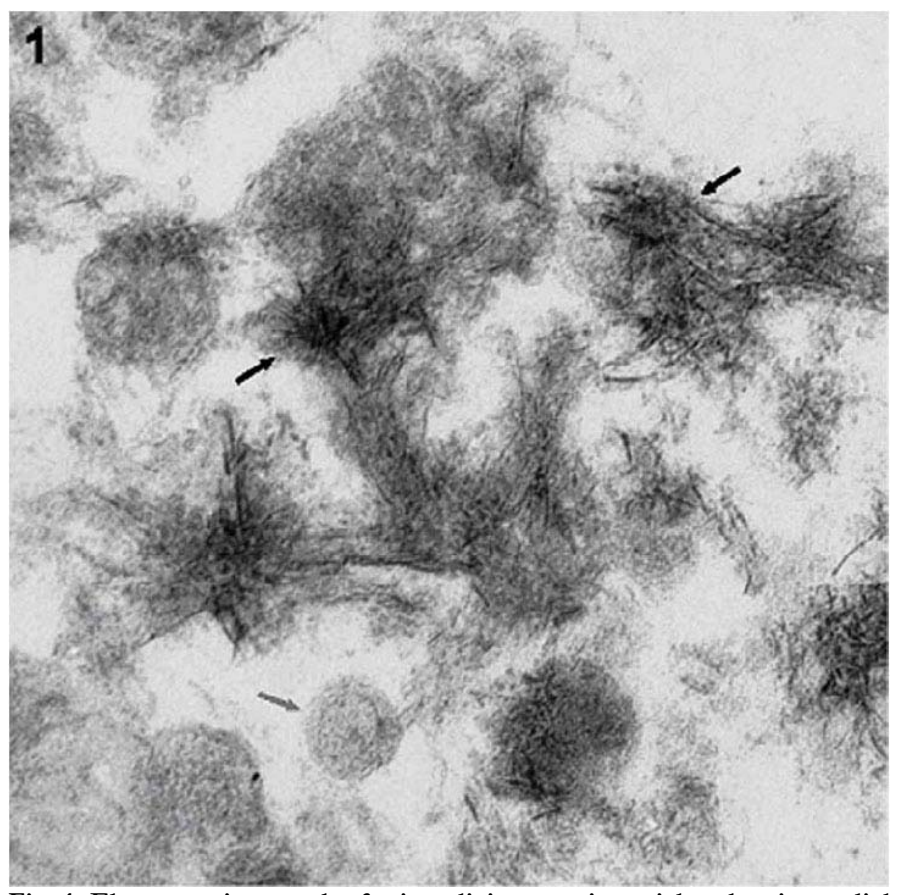

Fig. 1: Electron micrograph of mineralizing matrix vesicles showing radial clusters of hydroxyapatite like mineral (X 110,000). The dark arrows show needle shaped hydroxyapatite mineral while the grey arrow shows an intact MV. MVs isolated from growth plates of rachitic rats were calcified upon exposure to calcifying buffer containing physiological concentrations of $\mathrm{Ca}^{2+}$ and $\mathrm{Pi}$. The calcified MVs were fixed in $2.5 \%$ glutaraldehyde, post fixed in $1 \%$ osmium tetraoxide, dehydrated, embedded in Spurr's low viscosity epoxy resin. Thin sections were cut and stained with uranyl acetate and lead citrate, and photographed using a Zeiss EM IOA electron microscope.

This assay is based on the following principle:

$$
\mathrm{Ca}^{2+}+\mathrm{O}-\mathrm{CPC} \stackrel{\text { Alkaline medium } \longrightarrow}{\longrightarrow} \begin{aligned}
& \mathrm{Ca}-\mathrm{O}-\mathrm{CPC} \text { Complex } \\
& \text { (purple color) } \\
& \\
& 575 \pm 5 \mathrm{~nm}
\end{aligned}
$$

This assay, based on the micro-method of calcium determination using O-cresolpthalein complexone dye (12), involves the reaction of calcium with $\mathrm{O}$-CPC to produce a purple complex at $\mathrm{pH}$ 10-12 with an absorbance maximum at $575 \pm 5 \mathrm{~nm}$. The intensity of the color is directly proportional to the concentration of calcium in the sample. This colorimetric assay has been previously used in cell cultures for determination of calcium (13, 14). This assay has also been used to determine calcium from trichloroacetic acid-extracted bone samples $(15,16)$. Here, in this paper we describe a novel application of this technique in studying MV-mediated calcification. The advantage of this colorimetric technique for studying MV-mediated nonradioactive in vitro calcification over the conventional ${ }^{45} \mathrm{Ca}$ radioactive procedure lies in its simple, direct, sensitive, highly specific and readily adaptable nature. This assay is linear from $0.1-5 \mathrm{mM}$ calcium concentration. There are very few nonradioactive methods that have been applied for determining calcium from mineralized matrix vesicles. Kirsch et al. (17) have used a fluorometric procedure for measuring $\mathrm{Ca}^{2+}$ uptake by matrix vesicles. This procedure is based on the determination of calcium by calculating the difference in fluorescence intensity of calcium bound Fura-2 in triton-lysed samples of matrix vesicles that were incubated for $24 \mathrm{~h}$ in synthetic cartilage lymph vs. fluorescence intensity of Fura- 2 bound calcium in triton-lysed samples of freshly isolated, non-incubated matrix vesicles (control). Other researchers such as Wu et al. (18) have used Baginski's procedure (19) for calcium analysis from acid extracted samples of calcified matrix vesicles.

\section{MATERIALS AND METHODS}

\section{Induction of rickets}

Rickets was induced in male weanling Sprague Dawley rats by housing weanling rats in a dark room and feeding them a diet low in phosphorous and Vitamin D (20). After 4 weeks on rachitogenic diet, the rats were sacrificed according to the guidelines of the Institutional Animal Care and Use Committee (University of Kansas Medical Center), and their hypomineralized tibial and femoral growth plate were dissected for further isolation of chondrocytes and MVs. The rationale for using rachitic rat growth plate is that it provides an ideal model for studying MV initiated in vitro calcification without complication from propagation of pre-existing mineral.

\section{Isolation of MVs from rachitic rat growth plates}

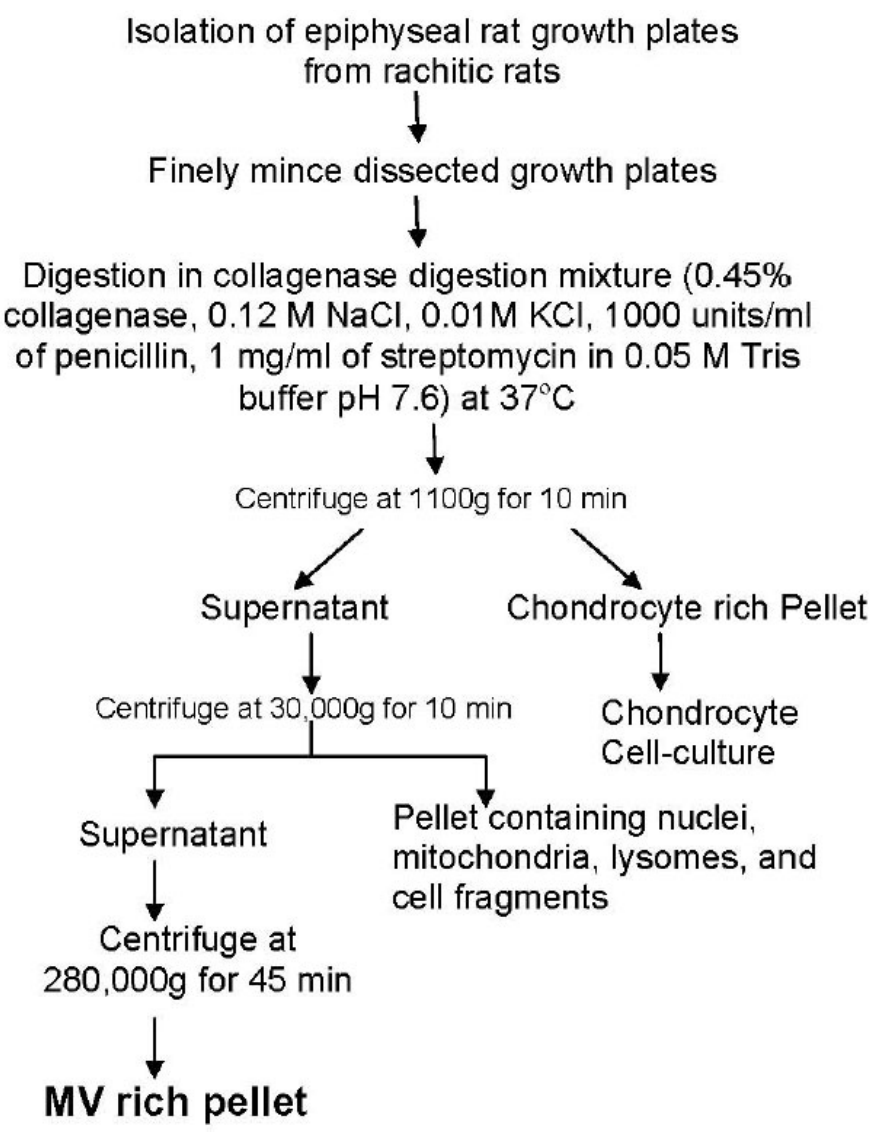

Fig. 2: Flow diagram showing the isolation of rat growth plate matrix vesicles (as described in (3) and (21)). 
MVs were isolated from rachitic rat growth plates by collagenase digestion as described previously (21). The isolation of matrix vesicles from rat growth plates is shown as a flow chart in Figure 2. Briefly, epiphyseal growth plates from 30 rats were dissected and finely minced. The minced tissue was then digested in a collagenase digestion mixture containing $0.45 \%$ collagenase (Boehringer Mannheim), $0.12 \mathrm{M} \mathrm{NaCl}, 0.01 \mathrm{M} \mathrm{KCl}, 1000$ units $/ \mathrm{ml}$ of penicillin, $1 \mathrm{mg} / \mathrm{ml}$ of streptomycin, and $0.05 \mathrm{M}$ Tris buffer $\left(\mathrm{pH} 7.6\right.$ at $37^{\circ} \mathrm{C}$ ). Collagenase digestion was done at $37^{\circ} \mathrm{C}$ for $3 \mathrm{~h}$. The collagenase digest was then centrifuged at $1100 \mathrm{~g}$ for $10 \mathrm{~min}$ to harvest cells. This pellet was used for in vitro culture of chondrocytes (4-7). The supernatant was subjected to a two-step differential ultra-centrifugation for the isolation of MVs. The first step involves the centrifugation of collagenase digest at $30,000 \mathrm{X}$ $\mathrm{g}$ for $10 \mathrm{~min}$ to remove nuclei, mitochondria, lysosomes and smaller cell fragments. The supernatant was then further centrifuged at 280,000X $\mathrm{g}$ for $45 \mathrm{~min}$. to obtain a highly pure MV pellet. The yield of MVs was estimated by measuring the protein content by Bradford assay (Biorad) and alkaline phosphatase specific activity of the micro-vesicle fractions released from collagenase-digested growth plates (Alkaline phosphatase specific activity by Sigma Diagnostic Kit-104LS). Briefly, a small volume of MV suspension was added to the ALP assay mixture containing p-nitrophenyl phosphate as substrate in $750 \mathrm{mM} 2$ amino, 2 methyl, 1-propanol ( $\mathrm{pH} 10.25)$ and $4 \mathrm{mM} \mathrm{MgCl}$. The absorbance of nitrophenol, a chromogenic product produced in the presence of ALP, was measured with a plate reader (Multiskan Plus; Fisher Scientific) at $405 \mathrm{~nm}$ (Millimolar absorbtivity of p-nitrophenol at $405 \mathrm{~nm}$ is $18.45 \mathrm{M}^{-1} \mathrm{~cm}^{-1}$ ).

\section{In vitro calcifiability of MVs}

Calcifiability of MVs isolated directly from growth plates (native) was assessed by non-radioactive calcium phosphate deposition assay. Briefly, this assay involves the incubation of $30 \mu \mathrm{g}$ samples of MV protein in a calcifying solution containing $2.2 \mathrm{mM} \mathrm{Ca}^{2+}$ and $1.6 \mathrm{mM} \mathrm{PO} 4^{3-}$ in the presence of 0 to $3 \mathrm{mM}$ phosphoester substrate, for example, ATP, AMP or $\beta$-GP in $0.05 \mathrm{M}$ Tris buffer $\left(\mathrm{pH} 7.6\right.$ at $37^{\circ} \mathrm{C}$ ) for $5.5 \mathrm{~h}$ at $37^{\circ} \mathrm{C}$. The incubation was terminated after $5.5 \mathrm{~h}$ by centrifugation at $8800 \mathrm{~g}$ for $30 \mathrm{~min}$. to co-precipitate MVs and calcium phosphate mineral formed during incubation. The pellet containing calcium phosphate mineral was then solubilized with $0.6 \mathrm{~N} \mathrm{HCl}$ for $24 \mathrm{~h}$. The calcium content of the $\mathrm{HCl}$ supernatant was then determined colorimetrically by the $O$-cresolpthalein complexone method (Calcium Kit, Procedure no. 587, Sigma-Aldrich Corporation, St. Louis, MO and Procedure No. 0150, Stanbio Laboratory, Boerne, TX). Briefly, $2 \mu \mathrm{l}$ of acidified supernatant was incubated with $200 \mu \mathrm{l}$ of calcium working reagent (Color Reagent + Base Reagent Mix) for 1 minute for microplate reader or $10 \mu \mathrm{l}$ of acidified supernatant with $1 \mathrm{ml}$ of calcium working reagent for UV-VIS spectrophotometer. The absorbance of calcium standard and calcium were read against blank at $570 \mathrm{~nm}$ within 60 minutes.

The standard curve of the assay is shown Figure 3. Protein content was measured using Bradford protein assay kit (BioRad). Samples were calibrated against a calcium standard $(10 \mathrm{mg} / \mathrm{dl}$,
Calcium kit, Sigma and Procedure No. 0150, Stanbio Laboratory), and absorption was measured at $575 \pm 5 \mathrm{~nm}$ using a spectrophotometer or microplate reader.

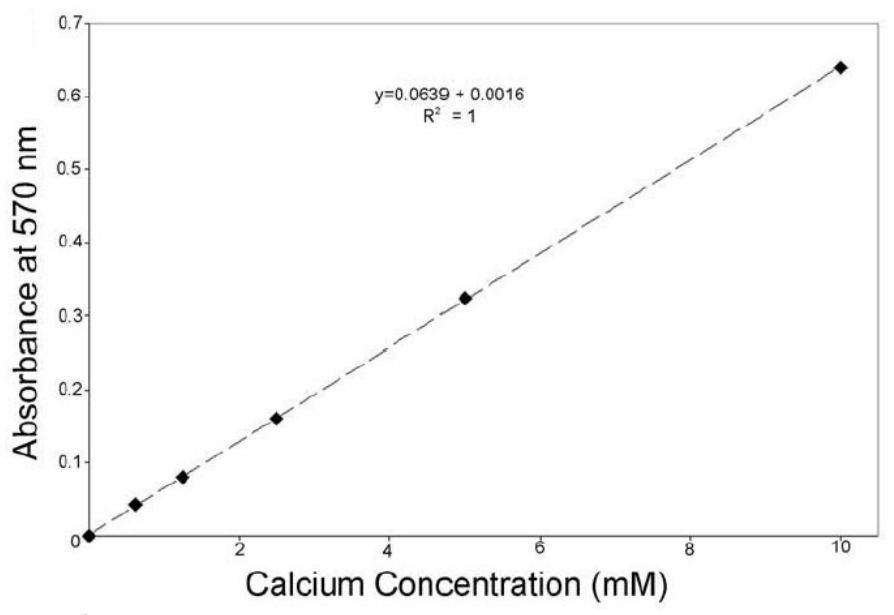

Fig. 3: Standard curve for o-cresolopthalein complexone assay.

\section{Statistical analysis}

Quantitative data are presented as mean \pm S.D. Statistical significance between groups was determined by analysis of variance (ANOVA) and paired t- test.

\section{RESULTS AND DISCUSSION}

We report here, a non-radioactive technique for studying MVmediated in vitro calcification. O-CPC assay was demonstrated here to be a convenient, sensitive and extremely relevant analytical method to study mineral initiation and mineral propagation by MVs. Using this assay, we report here that collagenase-released MVs from rachitic rat growth plates were able to deposit when exposed to calcifying buffer containing physiological concentrations of calcium and phosphate ions (Fig. 4).

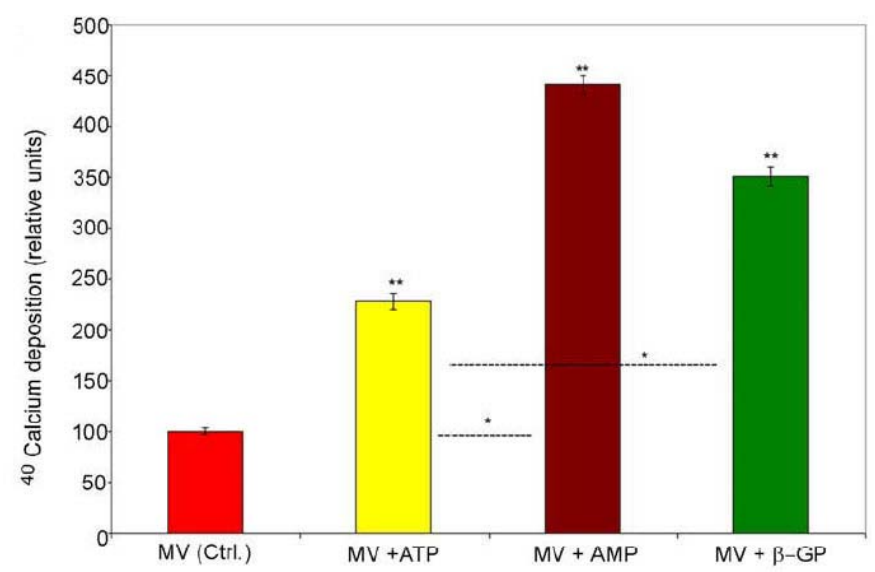

Fig. 4: Comparison of in vitro calcification profile of isolated MVs in the presence of $1 \mathrm{mM}$ ATP, $3 \mathrm{mM}$ AMP and $3 \mathrm{mM} \beta-\mathrm{GP}$ using $O-C P C$ assay. The calcium concentration is first obtained for each of the samples using calcium standard. The relative values are used to compare changes in the calcium 
deposition ability relative to the control reference sample (MVs in the absence of phosphoester substrates). Values are expressed as means \pm S.D. from five different MV preparations. Double asterisks are assigned to indicate the statistical significance $(\mathrm{P}<0.05)$ with respect to control. Single asterisks are assigned to indicate the statistical significance $(\mathrm{P}<0.05)$ between groups $(\mathrm{MV}+\mathrm{ATP}$ vs. $M V+A M P$, and MV+ATP vs. MV+ $\beta-G P)$.

Furthermore, we also show that AMP or $\beta$-GP (i.e. monophosphoester substrates for ALP and AMPase) were more effective in promoting calcium deposition by isolated MVs than ATP based on a comparable amount of phosphatase-releasable ester phosphate per one mole of ATP versus three moles of AMP or $\beta$-GP (Fig. 4). Our finding that monophosphoesters are better substrates of mineralization is consistent with the several reports on the role of $\beta$-GP in stimulating mineralization in osteoblast or chondrocyte in vitro cell cultures (22-26). This finding also draws further support from a kinetic study that demonstrated AMP and $\beta$-GP to be better substrates of alkaline phosphatase activity than ATP or ADP ( $\max$ values of $\beta$-GP was $76 \%$, AMP was $62 \%$ and ATP was $15 \%$ relative to $\mathrm{p}^{-}$ nitrophenylphosphate) (27). The finding that AMP and not ATP was present in high concentration in the mineralized regions of freeze-trapped endochondral cartilage of chick (28), further supports our results. Electron microscopic and X-ray diffraction studies on isolated MVs, calcified in vitro in the presence of AMP reveal the formation of hydroxyapatite crystals (29). Futhermore, only amorphous calcium pyrophosphate mineral was deposited by isolated human osteoarthritic MVs and rachitic rat MVs in the presence of ATP in mineralization assays $(30,31)$. The mechanism of enhanced mineralization by monophosphoesters such as AMP and $\beta$-GP is believed to be mediated by (a) increasing the local concentration of $\mathrm{Pi}(22-24)$ and (b) inhibiting the activity of NTPPPH $(23,32)$. One possible reason for monophosphoesters being better substrates for MVmineralization than ATP might be due to the generation of PPi during the hydrolysis of ATP by NTPPPH. PPi at concentrations higher than $1 \mathrm{mM}$ can inhibit mineralization (33).

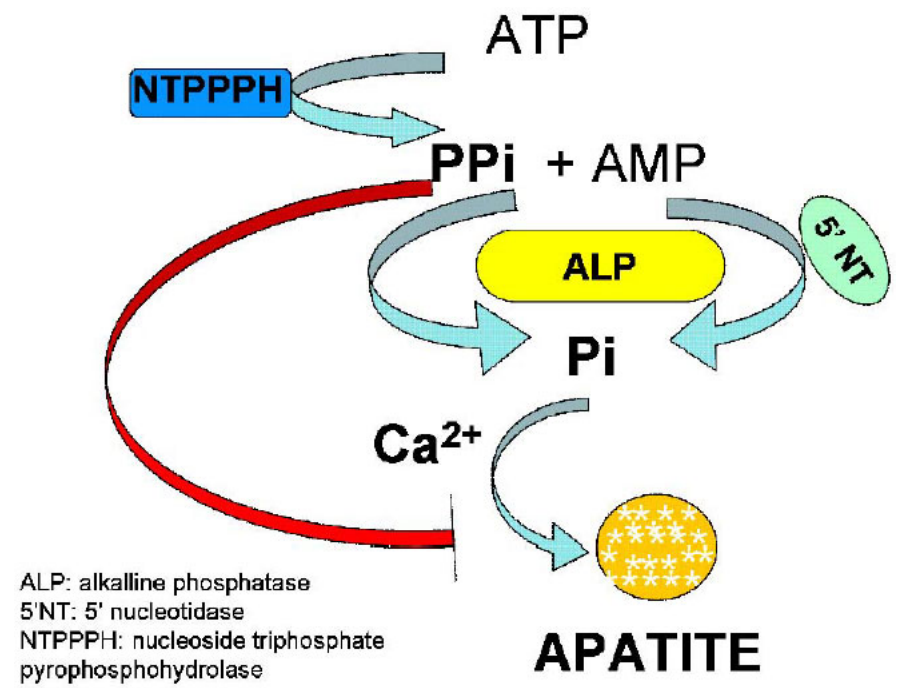
pyrophosphohydrolase

Fig. 5: Schematic diagram showing the metabolism of ATP and AMP and the effect of products of their hydrolysis on mineralization. ATP is hydrolyzed by nucleoside triphosphate pyrophosphohydrolase (NTPPPH) to $\mathrm{AMP}$ and inorganic pyrophosphate (PPi), which get further degraded to yield inorganic phosphate $(\mathrm{Pi})$ by alkaline phosphatase (ALP). The inorganic phosphate thus generated forms apatite in the presence of calcium of the extracellular fluid.
Excess accumulation of PPi prevents the transformation of amorphous calcium phosphate to hydroxyapatite (34-36). Thus, the steady state concentration of $\mathrm{PPi}$, maintained by concerted activities of NTPPPH and ALP (Fig. 5) regulates the formation and propagation of mature mineral. AMP, also formed during the hydrolysis of ATP by NTPPPH activity, is further metabolized to adenosine and Pi by 5' AMPase or ALPase. The mineral formed when isolated MVs were exposed to calcifying buffer containing AMP was identified as crystalline hydroxyapatite by Fourier transform infrared spectroscopy (data not shown).

\section{CONCLUSIONS}

The non-radioactive $O-C P C$ assay to study in vitro calcium deposition by isolated MVs, is simple and highly sensitive, and can offer a useful alternative approach to the routinely used radiometric biomineralization assay which employs radioactive ${ }^{45} \mathrm{Ca}$. Application of this technique for studying in vitro nonradioactive calcium deposition by isolated $\mathrm{MVs}$, demonstrates that monophosphoesters such as AMP and $\beta$-GP are better substrates of mineralization than ATP.

\section{ACKNOWLEDGMENTS}

This research was supported by National Institutes of Health Grant NIH-DEO5262.

\section{REFERENCES}

1. Anderson HC. Molecular biology of matrix vesicles. Clin Orthop Relat Res 1995; 314:266-280.

2. Anderson HC, Garimella R, Tague SE. The role of matrix vesicles in growth plate development and biomineralization. Frontiers in Bioscience 2005; 10:822-837.

3. Ali SY, Sajdera SW, Anderson HC. Isolation and characterization of calcifying matrix vesicles from epiphyseal cartilage. Proc Natl Acad Sci USA 1970; 67:1513-1520.

4. Anderson HC, Stechschulte Jr. DJ, Collins DE, Jacobs DH, Morris DC, Hsu HHT, Redford PA, Zeiger S. Matrix vesicle biogenesis in vitro by rachitic and normal rat chondrocytes. American Journal of Pathology 1990; 31:391-398.

5. Dhanyamraju R, Sipe JB, Anderson HC. Chondrogenic and osteogenic differentiation of primary cultures of rat growth plate chondrocytes. J Bone Min Res 2000; 15(Suppl 1):S381.

6. Dhanyamraju R, Sipe JB, Anderson HC. In vitro differentiation and matrix vesicle biogenesis in primary cultures of rat growth plate chondrocytes. In: Shapiro IM, Anderson HC, and Boyan BD editors. Growth Plate 2001, The Netherlands: IOS Press, Inc; 2002. p.127-138.

7. Garimella R, Bi X, Camacho N, Sipe J, Anderson HC. Primary culture of rat growth plate chondrocytes: an in vitro model of growth plate histotype, matrix vesicle biogenesis and mineralization. Bone 2004; 36:961-970.

8. Fedde KN. Human osteosarcoma cells spontaneously 
release matrix-vesicle-like structures with the capacity to mineralize. Bone \&o Min 1992; 17:145-151.

9. Glaser JH, Conrad HE. Formation of matrix vesicles by cultured chick embryo chondrocytes. J Biol Chem 1981; 256:2607-2611.

10. Kirsch T, Nah HD, Shapiro IM, Pacifici M. Regulated production of mineralization competent matrix vesicles in hypertrophic chondrocytes. J Cell Biol 1997; 137:1149-1160.

11. Wuthier RE, Chin JE, Hale JE, Register TC, Hale LV, Ishikawa Y. Isolation and characterization of calcium accumulating matrix vesicles from chondrocytes of chicken epiphyseal growth plate cartilage in primary culture. I Biol Chem 1985; 260:15972-15979.

12. Sarkar BC, Chauhan UP. A new method for determining micro quantities of calcium in biological materials. Anal Biochem 1967; 20:155-166.

13. Jono S, Nishizawa Y, Shioi A, Morii H. 1,25Dihydroxyvitamin D3 increases in vitro vascular calcification by modulating secretion of endogenous parathyroid hormone-related peptide. Circulation 1998; 98:1302-1306.

14. ter Brugge PJ, Wolke JG, Jansen JA. Effect of calcium phosphate coating composition and crystallinity on the response of osteogenic cells in vitro. Clin Oral Implants Res 2003; 4:472-480.

15. Whitfield JF, Morley P, Ross V, Preston E, Soska M , Barbier JR, Isaacs RJ, Maclean S, Ohannessian-Barry L, Willick GE. The hypotensive actions of osteogenic and nonosteogenic parathyroid hormone fragments. Calcif Tissue Int 1997; 60:302-308.

16. Ganta DR, McCarthy MB, Gronowicz GA. Ascorbic Acid Alters Collagen Integrins in Bone Culture. Endocrinology 1997; 138:3606-3612.

17. Wang W, Kirsch T. Retinoic acid stimulates annexinmediated growth plate chondrocyte mineralization. J Cell Biol 2002; 157:1061-1069.

18. Wu LN, Genge BR, Dunkelberger DG, LeGeros RZ, Concannon B, Wuthier RE. Physicochemical characterization of the nucleational core of matrix vesicles. $J$ Biol Chem 1997; 272:4404-4411.

19. Baginski ES, Marie SS, Clark WL, Zak B. Direct microdetermination of serum calcium. Clin Chim Acta 1973; 46:49-54.

20. McCollum EV, Simmonds N, Becker JE, Shipley PG. Studies on experimental rickets. XXI. An experimental demonstration of the existence of a vitamin which promotes calcium deposition. J Biol Chem 1922; 53:293-312.

21. Hsu HH, Anderson HC. A simple and defined method to study calcification by isolated matrix vesicles. Effect of ATP and vesicle phosphatase. Biochim Biophys Acta 1977; 500:162172.

22. Bellows CG, Aubin JE, Heersch JNM. Initiation and progression of mineralization of bone nodules formed in vitro: the role of alkaline phosphatase and organic phosphate. Bone \& Min 1991; 14:27-40.

23. Boskey AL, Guidon P, Doty SB, Stiner D, Leboy P,
Binderman I. The mechanism of beta-glycerophosphate action in mineralizing chick limb-bud mesenchymal cell cultures. J Bone Miner Res 1996; 11:1694-1702.

24. Chung CH, Golub EE, Forbes E, Tokuoka T, Shapiro IM. Mechanism of action of $\beta$-glycerophosphate on bone cell mineralization. Calcif Tissue Int 1992; 51:305-311.

25. Robison R. The possible significance of hexaphosphoric acid esters in ossification. Biochem J 1923; 17:286-293.

26. Sakamoto S, Sakamoto M, Goldberg L, Colarusso L, Gotah Y. Mineralization induced by beta-glycerophosphate in cultures leads to a marked increase in collagenase synthesis by mouse osteogenic MCT3 E1 cells under subsequent stimulation with heparin. Biochem Biophys Res Commun 1989; 162:773-780.

27. Ikehara Y, Mansho K, Takahashi K, Kato K. Purification and characterization of alkaline phosphatase from plasma membranes of rat ascites hepatoma. J Biochem (Tokyo) 1978; 83:1471-1483.

28. Matsumoto H, Golub EE, Shapiro IM. Is superoxide required for matrix vesicle formation? In: Ali SY editors. Cell mediated calcification and matrix vesicles. The Netherlands: Elsevier Science Publishers; 1986. p. 241-245.

29. Murphree S, Hsu HH, Anderson HC. In vitro formation of crystalline apatite by matrix vesicles isolated from rachitic rat epiphyseal cartilage. Calcif Tissue Int 1982; 34(Suppl 2):S6268.

30. Derfus B, Kranendonk S, Camacho N, Mandel N, Kushnaryov V, Lynch K, Ryan L. Human osteoarthritic cartilage matrix vesicles generate both calcium pyrophosphate dihydrate and apatite in vitro. Calcif Tissue Int 1998; 63:258-262.

31. Hsu HH, Camacho NP, Anderson HC. Further characterization of ATP-initiated calcification by matrix vesicles isolated from rachitic rat cartilage. Membrane perturbation by detergents and deposition of calcium pyrophosphate by rachitic matrix vesicles. Biochim Biophys Acta 1999; 1416:320-332.

32. Caswell AM, Ali SY, Graham R, Russell G. Nucleoside triphosphate pyrophosphatase in skeletal tissues. In: Ali SY editors. Cell mediated calcification and matrix vesicles. The Netherlands: Elsevier Science Publishers; 1986. p.101-106.

33. Fleisch H, Bisaz S. Mechanism of calcification: inhibitory role of pyrophosphate. Nature 1962; 195:911.

34. Termine JD, Kleinman HK, Whitson SW, Conn KM, McGarvey ML, Martin GR. Osteonectin, a bone-specific protein linking mineral to collagen. Cell 1981; 26:99-105.

35. Hessle L, Johnson KA, Anderson HC, Narisawa S, Sali A, Goding JW, Terkeltaub R, Millan JL. Tissue-nonspecific alkaline phosphatase and plasma cell membrane glycoprotein-1 are central antagonistic regulators of bone mineralization. Proc Natl Acad Sci USA 2002; 99:9445-9449.

36. Anderson HC, Sipe JB, Hessle L, Dhanyamraju R, Atti E, Camacho NP, Millan JL. Impaired calcification around matrix vesicles of growth plate and bone in alkaline phosphatase-deficient mice. Am J Pathol 2004; 164:841-847. 